\title{
Depth Research of Emergency Logistics Management information systems
}

\author{
Daqing $\mathrm{Li}$ \\ College of Management, BoHai University \\ Jinzhou, 121000, china \\ E-mail: jzldq@sohu.com
}

Keywords: Emergency Logistic ; Information System; Evaluation ; Set Pair Analysis

\begin{abstract}
In order to promote the constructing and maturing of Emergency logistics management information systems and improve the response speed to respond to emergencies, I made some survey about some major cities. Setting up a comparatively well-developed evaluation methodology of emergency logistics management information systems, and use pair analysis to calculate the date we got, ideally quantifiable evaluation answer is reached. Result of the calculation states the advantages and disadvantages of emergency logistics management information systems mentioned above. In this paper, set pair analysis was used to calculate the evaluation system. This approach has the great advantage, because it uses qualitative and quantitative analysis to calculate. This model was compact and simple. It is more suitable for the calculation of emergency logistics management information systems. The evaluation system suggested above solved the assessment problem, meanwhile, it has significant meaning for developing Emergency logistics management information systems.
\end{abstract}

\section{INTRODUCTION}

In recent years, disasters occurred frequently in China, such as floods, snowstorms, mine disasters and avian influenza ${ }^{[1]}$.In particular, unprecedented freezing rain and snowy weather stroked south China at the end of 2010 and at that time traffic in many cities paralyzed. All kinds of accidents caused enormous economic losses and casualties. In these events, most losses were caused by inadequate emergency logistic system in extreme environments. When these public events were happened, it is a key issue to figure out how to use emergency logistics management information systems to fast and accurate transmission of information. A well developed emergency logistics management information systems will reduce the economic and human losses as well as reflect the urban ability to deal with emergent cases.

\section{CONSTRUCTION OF EMERGENCY LOGISTICS INFORMATION EVALUATION SYSTEM}

The Meaning and Characteristics of Emergency logistics Management information systems. Emergency logistics management information systems is made to meet the sudden demand for logistic. It is an organic whole which consists of the production source of emergency logistics information and recipients of emergency logistics information, Information transmission channels which interrelated and mutually coordinated.

Having the main feature of urgent, Emergency logistics management information systems holds a main objective which is the minimum loss and to create maximum time and efficiency. Economic effectiveness is no longer the core target of the system. The system must rapidly respond and meet demands. That is the main target of emergency logistics management information systems, to be satisfactory and rapid. We hope that the emergency logistics management information systems can provide correct information at the right time, right place and to minimize emergency logistics costs.

The Function of emergency logistics management information systems in Emergencies. The speed of response to emergencies will affect efficiencies of emergency system, therefore, in the emergency system the emergency logistics management information systems is in a pivotal position. 
High quality of the system will usefully reduce the losses and damages. Thus, constructing and building a perfect and effective evaluation system for emergency response system play a quite important role for the city.

Construction of Evaluation System. In order to build a better emergency logistics management information systems, this paper proposed the evaluation system to improve the efficiency of logistic systems. There are four most important factors in emergency logistics management information systems: Ability to manage management information systemss, Ability of information collection, Ability of information transmission, Ability to receive information. In evaluation system, I put the four points as first level indicators. In this four first level evaluation, I put ten secondary level evaluations in TABLE ${ }^{[2]}$.Among all these indicators, they have different importance, and we lay different attention to them when using. For example, in Ability to manage management information systemss the Planning information is the key in emergencies. So it should be attachd with great importance to.This paper will give the value of evaluation system in the model, and some adjustments shall be made in real cases when it is different ${ }^{[3]}$.

\section{EVALUATION METHODOLOGY OF EMERGENCY LOGISTICS MANAGEMENT INFORMATION SYSTEMS}

Construction of evaluation matrix. There are $\mathrm{N}$ evaluation objects which are $\mathrm{M} 1, \mathrm{M} 2, \ldots \mathrm{Mn}$ in system. Each object has 10 indexes. Each index has a value tag: $\operatorname{dij}(i=1,2, \ldots, m ; j=1,2, \ldots, n)$. Multiobjective matrix with dimension base Set Pair Analysis:

$$
\mathrm{H}=\left[\begin{array}{cccc}
d_{11} & d_{12} & \cdots & d_{1 n} \\
d_{21} & d_{22} & \cdots & d_{2 n} \\
\vdots & \vdots & \ddots & \vdots \\
d_{m 1} & d_{m 2} & \cdots & d_{m n}
\end{array}\right]
$$

TABLE 1 Evaluation System for emergency logistics management information systems

\begin{tabular}{|c|c|c|}
\hline Target layer & First Level indicators & Secondary indicators \\
\hline \multirow{10}{*}{$\begin{array}{l}\text { Emergency efficient } \\
\text { management information } \\
\text { systems }(\mathrm{A})\end{array}$} & \multirow{4}{*}{$\begin{array}{l}\text { Ability to manage } \\
\text { management information } \\
\text { systemss (A1) }\end{array}$} & Planning information (A11) \\
\hline & & Equipment organization(A12) \\
\hline & & Staff efficiency(A13) \\
\hline & & System planning (A14) \\
\hline & \multirow{2}{*}{$\begin{array}{l}\text { Ability of information } \\
\text { collection(A2) }\end{array}$} & $\begin{array}{l}\text { The speed of information } \\
\text { collection (A21) }\end{array}$ \\
\hline & & $\begin{array}{l}\text { The accuracy of the information } \\
\text { collection (A22) }\end{array}$ \\
\hline & \multirow{2}{*}{$\begin{array}{l}\text { Ability of information } \\
\text { transmission (A3) }\end{array}$} & Transmission efficiency (A31) \\
\hline & & Guarantee transmission (A32) \\
\hline & \multirow{2}{*}{$\begin{array}{l}\text { Ability to receive } \\
\text { information(A4) }\end{array}$} & $\begin{array}{l}\text { Understanding of Information } \\
\text { (A41) }\end{array}$ \\
\hline & & The speed of understanding(A42) \\
\hline
\end{tabular}

Determination of indicator values for the matrix is as following: secondary indicators will be rated by experts and they will do the choice question: A: Satisfaction B: Medium C: Dissatisfied $^{[3]}$.Suppose there are $\mathrm{n}$ experts evaluate this indicator and $\mathrm{x}$ experts select $\mathrm{A}$, so dij=x/n, Ideal solution M0 [ $\mathrm{d} 01 \mathrm{~d} 02 \cdots \mathrm{d} 0 \mathrm{j} \mathrm{d} 0 \mathrm{~m}$ ]T, in which $\mathrm{d} 0 \mathrm{j}$ is the value of $\mathrm{j}$ indicator, at the same time, $\mathrm{d} 0 \mathrm{j}$ is the optimal value in $\mathrm{j}(\mathrm{j}=1,2, \ldots, \mathrm{m})$ of $\mathrm{H}$ matrix.

Compare of indicator values $\mathrm{d}_{\mathrm{ij}}$ of evaluation matrix and the index value $\mathrm{d}_{0 \mathrm{j}}$ in ideal solution, they can form a matrix Q: 


$$
\mathrm{Q}=\left[\begin{array}{cccc}
a_{11} & a_{12} & \cdots & a_{1 n} \\
a_{21} & a_{22} & \cdots & a_{2 n} \\
\vdots & \vdots & \ddots & \vdots \\
a_{m 1} & a_{m 2} & \cdots & a_{m n}
\end{array}\right]
$$

In this matrix, $a_{i j}$ is called the same degree of Index value of the evaluated object $d_{i j}$.

Determine the weight of evaluation indexes. Weight factor is an important measure of the degree in various indicators of the overall. In emergency logistics management information systems, each index has different importance in set pair analysis [4]. So each index should have a unique weight coefficient to reflect the different effects in the results. There are four methods to determine weight coefficient: Expert scoring; Independent number; AHP; WAS System. In this paper chose WAS System method to determine the weight of coefficient. WAS system method is based on gathering statistics to determine the weight. We can use this method to determine the weight coefficient of first level indicators: WA $=(0.42,0.20,0.20,0.18)$; the weight coefficient of second level indicators: WA $1=(0.25,0.25,0.26,0.24), \mathrm{WA} 2=(0.59,0.41), \mathrm{WA} 3=(0.55,0.45), \mathrm{WA} 4=(0.56,0.44)$.

Construction of comprehensive evaluation model. Ideal solution matrix $\mathrm{R}$ can be determined by Weight vector $\mathrm{W}$ and matrix $\mathrm{Q}$.

$$
\mathrm{R}=\mathrm{W} \times \mathrm{Q}=(\mathrm{W} 1, \mathrm{~W} 2, \cdots, \mathrm{Wm}) \times\left[\begin{array}{cccc}
a_{11} & a_{12} & \cdots & a_{1 n} \\
a_{21} & a_{22} & \cdots & a_{2 n} \\
\vdots & \vdots & \ddots & \vdots \\
a_{m 1} & a_{m 2} & \cdots & a_{m n}
\end{array}\right]=(\mathrm{a} 1, \mathrm{a} 2, \cdots, \mathrm{an})
$$

The element $a_{i}(j=1,2, \cdots, n)$ is the evaluation objective which is the same with the ideal scheme. According to the value of Ai matrix $\mathrm{R}$ we can decide the order of good or bad. The lager of the value $\mathrm{a}_{\mathrm{i}}$ the better is the evaluation objects.

\section{SAMPLE-ANALYSING OF EMERGENCY LOGISTICS MANAGEMENT INFORMATION SYSTEMS}

Now I use the above model to evaluate the emergency logistic management information systems in six major cities in China.

Data collecting. According to the setting of the above indicators, model to collected 6 cities data in China is in TABLE 2.

TABLE 2 Six Major Cities in China Emergency Logistic management information systems Scoring Table ${ }^{[5]}$

\begin{tabular}{|c|c|c|c|c|c|c|c|}
\hline $\begin{array}{c}\text { Level } \\
\text { indicators }\end{array}$ & $\begin{array}{c}\text { Secondary } \\
\text { indicators }\end{array}$ & $\begin{array}{c}\text { City } \\
1\end{array}$ & $\begin{array}{c}\text { City } \\
2\end{array}$ & $\begin{array}{c}\text { City } \\
3\end{array}$ & $\begin{array}{c}\text { City } \\
4\end{array}$ & $\begin{array}{c}\text { City } \\
5\end{array}$ & $\begin{array}{c}\text { City } \\
6\end{array}$ \\
\hline \multirow{3}{*}{ A1 } & A11 & 0.66 & 0.71 & 0.76 & 0.61 & 0.72 & 0.82 \\
\cline { 2 - 8 } & A12 & 0.75 & 0.85 & 0.83 & 0.91 & 0.70 & 0.74 \\
\cline { 2 - 8 } & A13 & 0.79 & 0.88 & 0.86 & 0.89 & 0.93 & 0.90 \\
\cline { 2 - 8 } & A14 & 0.85 & 0.88 & 0.94 & 0.82 & 0.91 & 0.85 \\
\hline \multirow{4}{*}{ A2 } & A21 & 0.70 & 0.68 & 0.65 & 0.75 & 0.66 & 0.76 \\
\cline { 2 - 8 } & A22 & 0.78 & 0.80 & 0.72 & 0.75 & 0.70 & 0.82 \\
\hline \multirow{2}{*}{ A3 } & A31 & 0.80 & 0.86 & 0.85 & 0.88 & 0.86 & 0.84 \\
\cline { 2 - 8 } & A32 & 0.86 & 0.85 & 0.88 & 0.86 & 0.84 & 0.81 \\
\hline A4 & A41 & 0.70 & 0.87 & 0.90 & 0.95 & 0.88 & 0.85 \\
\hline & A42 & 0.60 & 0.65 & 0.63 & 0.58 & 0.67 & 0.64 \\
\hline
\end{tabular}




\section{Evaluation of the secondary indicators}

First, I get matrix HA1 from TABLE II :

$$
\mathrm{H}=\left[\begin{array}{llllll}
0.66 & 0.71 & 0.76 & 0.61 & 0.72 & 0.82 \\
0.75 & 0.85 & 0.83 & 0.91 & 0.70 & 0.74 \\
0.79 & 0.88 & 0.86 & 0.89 & 0.93 & 0.90 \\
0.85 & 0.88 & 0.94 & 0.82 & 0.91 & 0.85
\end{array}\right]
$$

Ideal solution: $\mathrm{M} 0=\left[\begin{array}{llll}0.82 & 0.91 & 0.93 & 0.94\end{array}\right]^{\mathrm{T}}$, So

Evaluation results:

$$
\mathrm{QA} 1=\left[\begin{array}{cccccc}
0.83 & 0.81 & 0.93 & 0.73 & 0.96 & 1 \\
0.83 & 0.88 & 0.87 & 0.96 & 0.74 & 1 \\
0.86 & 0.96 & 0.95 & 1 & 0.77 & 0.88 \\
0.85 & 0.91 & 1 & 0.94 & 1 & 0.99
\end{array}\right]
$$

Ability to manage management information systemss: RA1 $=\mathrm{WAl} \times \mathrm{QA} 1=(0.88,0.92,0.93,0.91$, 0.90, 0.98).

Ability of information collection: RA2 $=\mathrm{WA} 2 \times \mathrm{QA} 2=(0.912,0.933,0.853,0.912,0.825,1)$.

Ability of information transmission: RA3 $=$ WA3 $\times \mathrm{QA} 3=(0.938,0.934,0.976,0.956,0.938,0.936)$

Ability to receive information: $\mathrm{RA} 4=\mathrm{WA} 4 \times \mathrm{QA} 4=(0.719,0.722,0.736,0.785,0.755,0.731)$.

Level I indicator. Evaluation results of Emergency Logistic System: RA=WA $\times \mathrm{QA}=(0.917,0.938$, $0.978,0.914,0.922,0.972$ )

Therefore, evaluation results of 6 major cities in China as follows: 0.917, 0.938, 0.978, 0.914, $0.922,0.972$. The order of city: city 3 , city 6 , city 2 , city 5 , city 1 , city 4 .

\section{CONCLUSION}

In a word, This paper proposed an evaluation system for emergency logistics management information systems base on summarizing the theory of emergency logistic system and successfully used set pair analysis model to calculate ${ }^{[9]}$. It can solve the problems of emergency logistics management information systems measurement effectively in many cities of our country. In this paper, set pair analysis was used to calculate the evaluation system. This approach has the great advantage, because it uses qualitative and quantitative analysis to calculate. This model was compact and simple ${ }^{[10]}$. It is more suitable for the calculation of emergency logistics management information systems.

\section{ACKNOWLEDGEMENTS}

Academy of Social Sciences Fund (L13BGL011) : Research on Collaborative Innovation

\section{REFERENCES}

[1] Gwyndaf Williams, Stuart Batho, Lynne Russell, "Responding to urban crisis - The emergency planning response to the bombing of Manchester city centre"Cities, vol.17(4),pp.293-304, 2009.

[2] Laurie Pearce, "Disaster Management and Community Planning and Public Participation:How to Achieve Sustainable Hazard Mitigation”, Natural Hazards, vol. 28,pp.211-228,2003.

[3] Laibao Wang, Emergency Logistics System, Higher Education Press,2008.

[4] Chenggen Zhao, City crisis management,Science and Technology Press,2007.

[5] Jianmin Liu, "Thoughts about Guarantee of Emergency Logistic System" Transportation and administration, vol 10,pp 128-130,2008.

[6] Lu Zheng, Chenchen Li,Jue Wang, “Analyses on Emergency Logistic Development in China and Existing problems". Transportation engineering and administration,vol.8,pp.63-64,2009. 
[7] Dyer J H, Kale P, Singh H. How to Make Strategic Alliances Work[J]. Sloan Management Review, 2001,42(4):37-43

[8] Das T K, Teng B S.A Resource-based Theory of Strategic Alliances[J].Journal of Management,2000,26(1),31-61

[9] laria G, pierpaolo P. Supply chain coordination by revenue sharing contract s [J].International Journal of Production,2004,6(89):131-139

[10] Nonaka I.Objectivity and Subjectivity in Knowledge Manage-ment:A Review of 20 Top Articles[J].Knowledge and ProcessManagement, 2006, 13(2):73-88 